\title{
Membrane Flash Index: Powerful and Perspicuous Help for Efficient Separation System Design
}

\author{
Andras Jozsef Toth,* Botond Szilagyi, Daniel Fozer, Eniko Haaz, Asmaa Khaled Mohamed Selim, \\ Milán Szöri, Bela Viskolcz, and Peter Mizsey
}

Cite This: https://dx.doi.org/10.1021/acsomega.0c01063

Read Online

\section{ACCESS 1}

Џlll Metrics \& More

Article Recommendations

Supporting Information

ABSTRACT: There are different factors and indices to characterize the performance of a pervaporation membrane, but none of them gives information about their capabilities in the area of liquid separation compared to the most convenient alternative, which is distillation. Membrane flash index (MFLI) can be considered the first and only one that shows if the membrane is more efficient or not than distillation and quantifies this feature too. Therefore, the MFLI helps select the best separation alternative in the case of process design. In this study, the evaluation and capabilities of membrane flash index are comprehensively investigated in the cases of six aqueous mixtures: methyl alcohol-water, ethyl alcohol-water, isobutyl alcohol-water, tetrahydrofuran-water, N-butyl alcoholwater, and isopropanol-water. It must be concluded that the separation capacity of organophilic type membranes is remarkably lower than hydrophilic membranes in all cases of separation. The study of the MFLI is extended with the consideration of other binary interaction parameters like separation factor, permeation flux, selectivity, and pervaporation separation index (PSI) in order to find a descriptive relationship between them. For the same membrane material type, descriptive function can be determined between feed concentration and MFLI and PSI and separation factor, which can be used to calculate each other's value. On the basis of the indices and especially the MFLI, a significant help can be given to the process design engineer to select the right liquid separation alternative and, in the case of pervaporation, find the most appropriate membrane.

\section{INTRODUCTION}

Flash distillation is a specific method within the whole of rectification and distillation processes, where a liquid mixture is warmed up and pumped into the distillation apparatus of reduced pressure with permanent stream. In steady-state operations, the combinations of two phases are permanent and in equilibrium. The liquid and vapor phases are fed into a decanter (phase separator) where they are treated separately. ${ }^{1,2}$

Pervaporation is a current operation for the treatment of aqueous mixtures with organic content. The pervaporation (PV) technology is mostly applied for dehydration of organic substances, ${ }^{3-9}$ separation of organic mixtures, ${ }^{10-13}$ and takeout of low-concentration organic substances from their mixtures. $^{14-20}$ The separated mixture passes over a phase change in the thin film material (membrane) on account of the used vacuum at the product part that results in the permeate being in the vapor phase. ${ }^{21-23}$ The mixture is separated by the sorption and diffusion features of a rather passing substance over a thin film membrane. ${ }^{1}$

Depending on the passing substance, pervaporation is classified into two major categories: hydrophilic pervaporation (HPV) and organophilic pervaporation (OPV). ${ }^{1,23-27}$ An enormous number of practical operations and publications represent the relevance of pervaporation as a separation process in the category of membranes. ${ }^{28,29}$ The effectiveness and the slight functional circumstances make pervaporation a profitable process in the field of separation methods. ${ }^{1,30}$

Inorganic zeolite and composite polydimethylsiloxane (PDMS) are the most used materials for organophilic pervaporation for discharge organic compounds from their mixtures. $^{31}$ Polyvinyl alcohol (PVA) is the generally used membrane type for hydrophilic pervaporation.,32

PV can be evaluated by various factors. Equation 1 describes the flux ${ }^{33}$ as

$$
J_{i}=\frac{P_{i}}{\Delta t \cdot A}
$$

where $P_{i}$ is the amount of substance $i$ in the permeate side, $A$ is the membrane surface area, and $\Delta t$ is the duration of the separation process. ${ }^{34,35}$ Equation 2 represents the calculation of separation $^{35}$ as

Received: March 9, 2020

Accepted: June 8, 2020 
Table 1. Evaluation and Summary of MFLIs, PSIs, and Separation Factors in Methanol-Water Separation (AVE, Average; SDV, Standard Deviation; MAX, Maximum)

\begin{tabular}{|c|c|c|c|c|c|c|c|c|c|c|}
\hline \multirow[b]{2}{*}{ org or hydr } & \multirow[b]{2}{*}{ membrane category } & \multicolumn{3}{|c|}{ MFLI } & \multicolumn{3}{|c|}{ PSI } & \multicolumn{3}{|c|}{ separation factor } \\
\hline & & $\mathrm{AVE}^{1}$ & $\mathrm{SDV}^{1}$ & $\mathrm{MAX}^{1}$ & AVE & SDV & MAX & AVE & SDV & MAX \\
\hline \multirow[t]{3}{*}{ organophilic membranes } & PDMS & 1.2 & 0.5 & 2.6 & 5 & 5 & 16 & 8 & 5 & 23 \\
\hline & hydrophobic zeolite & 2.3 & 0.7 & 3.6 & 17 & 28 & 95 & 30 & 28 & 100 \\
\hline & all type & 1.8 & 0.8 & 3.6 & 11 & 20 & 95 & 19 & 23 & 100 \\
\hline \multirow[t]{3}{*}{ hydrophilic membranes } & polyvinyl alcohol (PVA) & 14.5 & 9.2 & 24.2 & 112 & 275 & 889 & 481 & 602 & 1534 \\
\hline & other hydrophilic & 15.7 & 6.4 & 25.0 & 237 & 598 & 1889 & 246 & 450 & 1260 \\
\hline & all type & 15.1 & 7.7 & 25.0 & 175 & 457 & 1889 & 363 & 531 & 1534 \\
\hline
\end{tabular}

Table 2. Comparison of MFLIs with Separation Factors $(\alpha)$, Pervaporation Separation Indexes (PSIs), and Selectivities $(\beta)$ in Methanol-Water Pervaporation

\begin{tabular}{|c|c|c|c|c|c|c|}
\hline org or hydr & membrane category & $\alpha[-]$ & PSI $\left[\mathrm{kg} / \mathrm{m}^{2} \mathrm{~h}\right]$ & $\beta[-]$ & MFLI $[-]$ & ref. \\
\hline \multirow[t]{3}{*}{ orgPV } & PDMS/silica nanocomposite & 23 & 8 & 4.1 & 2.6 & Shirazi et al., $2012^{42}$ \\
\hline & silicalite-1, SS support & 14 & 13 & 2.3 & 1.8 & Liu et al., $1996^{43}$ \\
\hline & B-ZSM-5, $\alpha$-support s. & 12 & 1 & 1.9 & 1.6 & Bowen et al., $2003^{44}$ \\
\hline \multirow[t]{3}{*}{ hydrPV } & Polyamide-6 & 891 & 15 & 4097 & 24.8 & El-Gendi and Abdallah, $2013^{45}$ \\
\hline & composite PVA/P(AA-co-AN/SiO $\left.{ }_{2}\right)$ & 1534 & 889 & 963 & 24.2 & Peng et al., $2006^{46}$ \\
\hline & cross-linked chitosan & 9 & 4 & 714 & 15.5 & Won et al., $2003^{47}$ \\
\hline
\end{tabular}

$$
\alpha=\frac{y_{i} / y_{j}}{x_{i} / x_{j}}
$$

where $x_{i}, x_{j}$ and $y_{i}, y_{j}$ are concentrations of substances $i$ and $j$ in the feed side and the permeate side. It must be mentioned that the separation factor $(\alpha)$ is (dimensionless). ${ }^{35}$ Equation 3 shows the calculation of the pervaporation separation index (PSI):

$$
\text { PSI }=J \cdot(\alpha-1)
$$

Permeance can specify the performance of pervaporation membranes, which is normalized substance flux by the pressure divergence as impulsion: ${ }^{1,36}$

$$
\frac{P_{i}}{\delta}=\frac{J_{i}}{\gamma_{i 1} \cdot x_{i 1} \cdot p_{i 0}-y_{i} \cdot p_{3}}
$$

The ratio of permeances gives the selectivity $(\beta):^{1}$

$$
\beta=\frac{P_{i} / \delta}{P_{j} / \delta}
$$

In the literature, the pervaporation separation index, flux, and separation factor are generally applied for ranking the separation performances of different pervaporations. ${ }^{23}$ The listed factors are the functions of the inside attributions of the used material of membranes. However, the selectivity also depends on the functional circumstances, mainly permeate pressure, temperature, and compositions of feed. ${ }^{23}$ It can be mentioned that the promising direction of evaluation pervaporation achievement is the determination of selectivity; $^{36}$ nevertheless, a few research papers describe this parameter.

It has to be mentioned that the literature do not show a comprehensive clear approach for the comparison of separation effectiveness of pervaporation and its separation alternative, which is distillation. ${ }^{36}$ The relative vaporization in the distillation process is involved in the interpretation of selectivity by Baker. ${ }^{1,29}$ Nevertheless, this comparison does not result in a direct and simple correlation between distillation and pervaporation for process engineers. Hinchliffe and
Porter $^{37-39}$ have reported the cost-based comparison of membrane separation and distillation. Cost permeability has been defined and case studies have been plotted in the function of effective selectivity and this parameter. However, it is informative and really helpful for practice but very specific and difficult to generalize the comparison. Furthermore, the membrane prizes change quickly because this sector is innovative.

Considering pervaporation and flash distillation options, pervaporation can be compared to the characteristics of elementary flash distillation. Toth et al. ${ }^{1}$ created a simply method, which is mainly based on the comparison of available theoretical maximum distillate compositions. The main formula of the so-called membrane flash index (MFLI) is as follows:

$$
\text { MFLI }=\frac{y_{i}^{P V}}{y_{i}^{D}[\mathrm{VLE}]}
$$

where $y_{i}^{P V}$ is the permeate concentration and $y_{i}^{D}[\mathrm{VLE}]$ is the equilibrium distillation value. The comparison perspective of the MFLI focuses only on the separation abilities of the distillation and pervaporation operations. The prime preference of the membrane flash index is simplicity and accuracy because only two practical (experimental) data $\left(\alpha_{i}\right.$ and $\left.x_{i}^{F}\right)$ and the appropriate vapor-liquid equilibrium (VLE) data are enough for evaluation. The membrane flash index presents explicit comparison of distillation and pervaporation in the process and chemical engineering area. The separation achievement of PV is preferable than the application of flash distillation if the MFLI is above $1{ }^{1}$

In our previous paper, ${ }^{1}$ the calculation of the MFLI was described with one equilibrium model in detail. The purpose of this study is to evaluate the MFLI in the aspects of other descriptive quantities and to extend its calculation.

\section{RESULTS AND DISCUSSION}

In general, 10-15 assorted samples (membrane) with the highest membrane flash indexes are inspected in every case of the main group of membrane material types. Organophilic and 
hydrophilic separations are also investigated. The comparison and evaluation of pervaporation and flash distillation are introduced on the joint liquid-vapor equilibrium figure of binary mixtures. ${ }^{31,40,41}$ Calculated MFLIs and liquid-vapor equilibrium figures is found in the Supporting Information (Parts II, III, IV, V, VI, and VII). In decreasing order, the membrane flash indexes are shown in tables.

2.1. Separation of Methyl Alcohol-Water Mixture. Separation factors, MFLIs, and PSIs of pervaporation membranes of methanol-water binary mixtures are summarized in Table 1.

It can be concluded that PVA and other dehydration membranes are dominant in every hierarchy and organophilic pervaporation shows significantly worse separation efficiency than methanol dehydration. Table 2 introduces the highest results of MFLIs in the case of the different membrane types for which selectivity values were available in the research paper. The best three selectivities are introduced. In addition, the corresponding separation factors and PSI values are given to the comparison. The complete data set can be seen in Supporting Information, Part II/3.

It must be mentioned that there is no accordance between separation factor and PSI, e.g., the highest separation factor of the membrane type is not the highest in PSI value. In contrast, the membrane with the highest MFLI value has also the highest selectivity. Figures $1-3$ introduce a functional relationship between methanol feed weight fractions and PSIs and MFLIs and separation factors in the case of PDMS membranes.

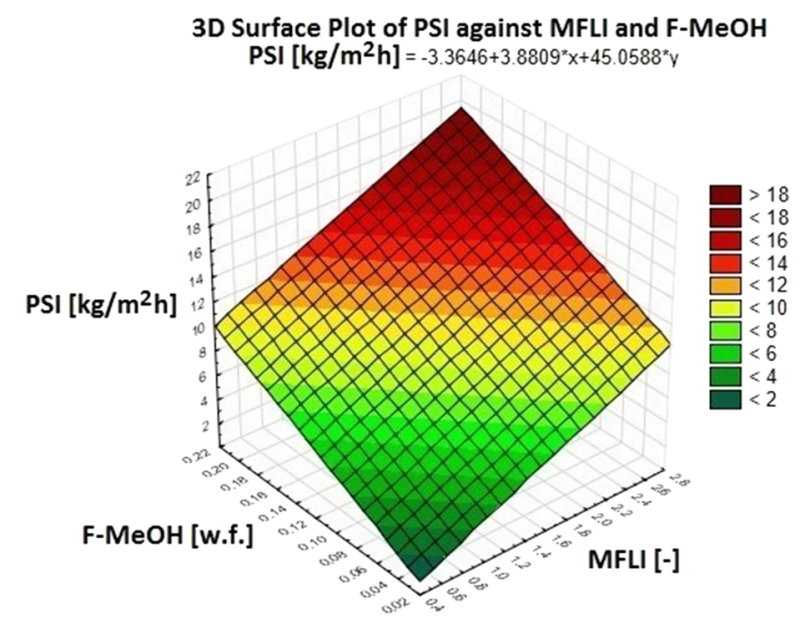

Figure 1. Influence of the PSIs and MFLIs on the methanol feed weight fractions in the case of methyl alcohol-water separation with PDMS membranes.

Figures 4-6 present a functional relationship between methanol feed weight fractions and PSIs and separation factors and MFLIs in the case of PVA type membranes. The Supporting Information contains the figures about zeolite membranes in the part of II/3.

2.2. Separation of Ethyl Alcohol-Water Mixture. Table 3 introduces the MFLI of pervaporation membranes of ethyl alcohol-water mixtures.

It can be mentioned that the parameters of dehydration membranes are dominant as seen with methanol-water separation. The highest values of MFLIs in the case of organophilic and hydrophilic types for which selectivity values

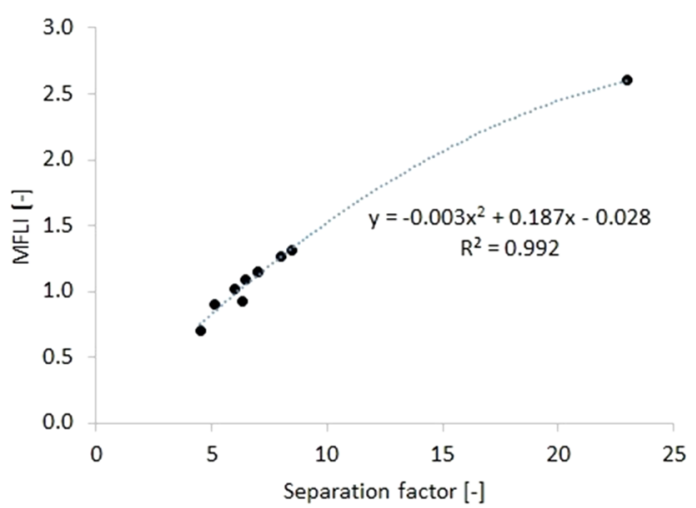

Figure 2. MFLI values in the function of separation factors in the case of methyl alcohol-water separation with PDMS membranes.

3D Surface Plot of Sep. factor against MFLI and F-MeOH

Sep. factor $[-]=-8.2424+1.9102^{*} x+226.5848^{*} y+2.5893^{*} x^{*} x+10.8672^{*} x^{*} y-918.076^{*} y * y$

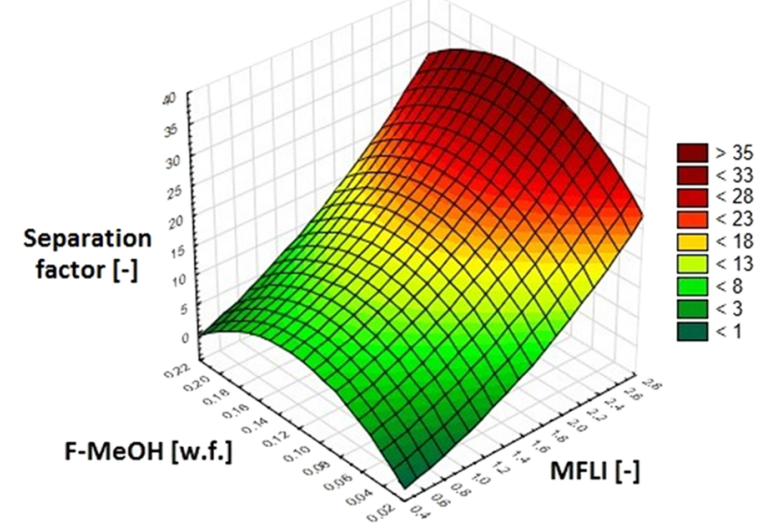

Figure 3. Influence of the separation factors and MFLIs on the methanol feed weight fractions in the case of methanol-water separation with PDMS membranes.

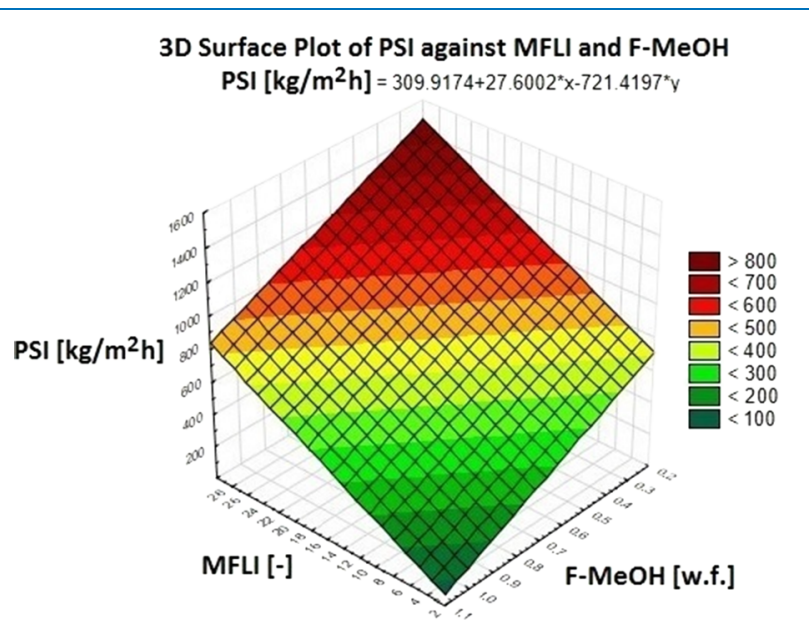

Figure 4. Influence of the PSIs and MFLIs on the methanol feed weight fractions in the case of methyl alcohol-water separation with polyvinyl alcohol membranes.

were available in the research paper can be seen in Table 4. Separations and PSI values were added; the complete data set can be seen in Supporting Information, Part III/3.

It can be said that the highest MLFIs have the highest selectivities too and there is no accordance between MFLIs and PSI values. The Supporting Information contains the 


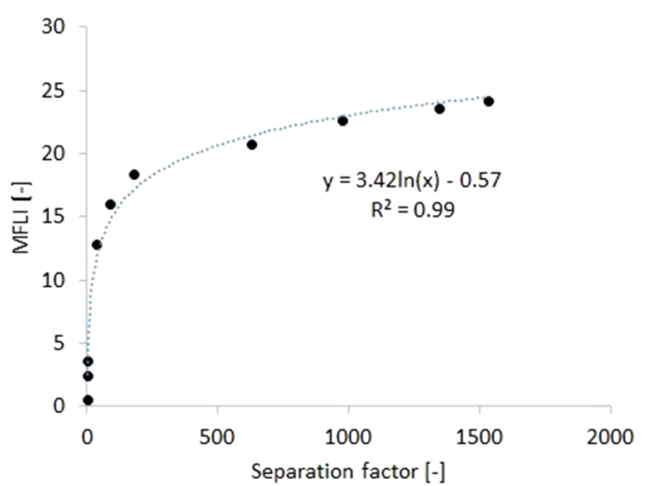

Figure 5. MFLI values in the function of separation factors in the case of methyl alcohol-water with PVA membranes.

3D Surface Plot of Sep. factor against MFLI and F-MeOH Sep. factor $[-]=3.2464+71.2761^{1} x-187.0982^{*} y+6.4232^{*} x^{*} x-193.6238^{*} x^{*} y+521.5382^{*} y^{*} y$

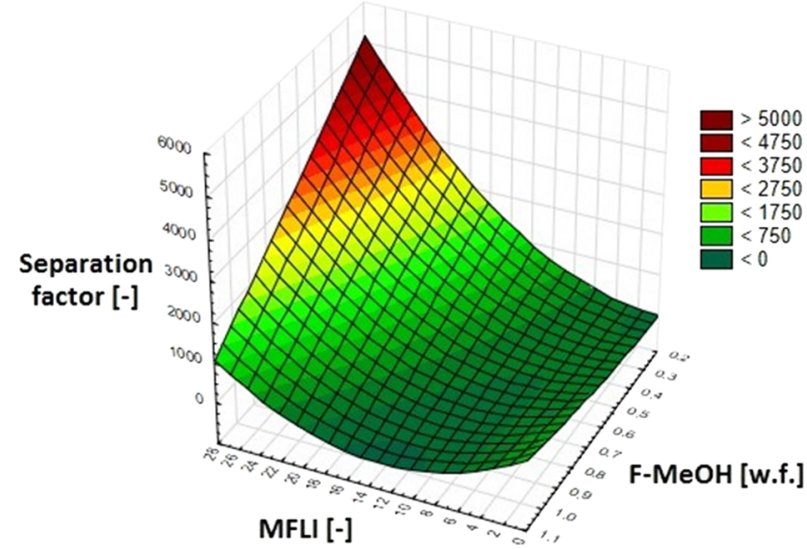

Figure 6. Influence of the separation factors and MFLIs on the methanol feed weight fractions in the case of methyl alcohol-water separation with polyvinyl alcohol membranes.

figures about the functional relationship between ethanol feed weight fractions and PSIs and separation factors and MFLIs in the case of PDMS, PVA, zeolite type membranes, and membranes containing charged group in the part of III/3.

2.3. Separation of Isobutanol-Water Mixture. It must be mentioned that there is remarkably less OPV and HPV membrane type for separation of heterogeneous azeotropic compounds from water. Table 5 introduces the MFLIs of membranes in the organophilic and hydrophilic pervaporations of isobutanol-water mixture.
Table 6 shows the comparison of the main descriptive quantities of IBU-water mixture.

Same tendencies and experience can be determined in separation of IBU-water binary mixture as in the case of ethyl alcohol and methyl alcohol. The Supporting Information contains a functional relationship between isobutanol feed weight fractions and PSIs and MFLIs in the case of PDMS and PVA membranes in the part of IV $/ 3$.

2.4. Separation of Tetrahydrofuran-Water Mixture. The comparison of separation factors, MFLIs, and PSIs of tetrahydrofuran-water mixture is summarized in Table 7.

2.5. Separation of $\mathbf{N}$-Butanol-Water Mixture. Table 8 summarizes the comparison of separation factors, MFLIs, and PSI of $N$-butanol-water mixture.

2.6. Separation of Isopropanol-Water Mixture. Table 9 summarizes the comparison of separation factors, MFLIs, and PSI of isopropanol-water mixture.

\section{CONCLUSIONS}

In the case of process synthesis, the final decision about the design of a liquid separation system has to consider environmental impacts, cost elements of methods, controllability, etc., in many cases. Membrane flash index (MFLI) gives preliminary information about the selection between pervaporation and distillation methods to help find the appropriate separation method. Moreover, if the membrane flash index value is relative high, the membrane separation should be preferred by far. So, a high value of MFLI shows not only the priority of pervaporation but gives also a heuristic judgment how far it is better. As our examples show that the MFLI can be only a bit higher than 1 , showing that pervaporation could be better, but the MFLI can be several orders of magnitude higher than 1 shows a superior performance of pervaporation over the distillation. On the contrary, if the membrane flash index is low, that is, near 1, flash distillation should be selected because that seems to be the better choice.

The separation capacities of six binary, aqueous mixtures are investigated. MFLIs, separation factors, total fluxes, pervaporation separation indices, and selectivity values are evaluated. Three thermodynamic models are introduced for the calculation of MFLIs to generalize the description. It can be determined that the dehydration type membranes have remarkably higher separation capacities in all investigated cases than the organophilic membranes.

To harmonize the MFLI with the other membrane parameters/indices, it is necessary to find the connection between these evaluation parameters to give support for

Table 3. Evaluation and Summary of MFLIs, PSIs, and Separation Factors in Ethanol-Water Separation

\begin{tabular}{|c|c|c|c|c|c|c|c|c|c|c|}
\hline \multirow[b]{2}{*}{ org or hydr } & \multirow[b]{2}{*}{ membrane category } & \multicolumn{3}{|c|}{ MFLI } & \multicolumn{3}{|c|}{ PSI } & \multicolumn{3}{|c|}{ separation factor } \\
\hline & & $\mathrm{AVE}^{1}$ & $\mathrm{SDV}^{1}$ & $\operatorname{MAX}^{1}$ & AVE & SDV & MAX & AVE & SDV & MAX \\
\hline \multirow[t]{5}{*}{ organophilic membranes } & PDMS & 1.4 & 0.3 & 1.9 & 5 & 6 & 20 & 10 & 2 & 14 \\
\hline & other polymeric & 2.2 & 0.2 & 2.7 & 11 & 14 & 49 & 23 & 7 & 46 \\
\hline & hydrophobic zeolite & 3.2 & 0.7 & 4.5 & 36 & 38 & 129 & 57 & 28 & 125 \\
\hline & silicalite-silicone rubber mixed matrix & 2.0 & 0.6 & 3.1 & 2 & 3 & 9 & 21 & 16 & 59 \\
\hline & all type & 2.2 & 0.8 & 4.5 & 15 & 25 & 129 & 28 & 25 & 125 \\
\hline \multirow[t]{5}{*}{ hydrophilic membranes } & polyvinyl alcohol (PVA) & 13.0 & 5.1 & 20.2 & 32 & 52 & 178 & 367 & 267 & 893 \\
\hline & chitosan-based & 15.5 & 6.1 & 25.0 & 171 & 357 & 1175 & 2173 & 3013 & 10,491 \\
\hline & membranes containing charged groups & 16.5 & 7.2 & 33.2 & 1397 & 3315 & 10,299 & 2966 & 4455 & 11,600 \\
\hline & membranes formed from polysalts & 11.0 & 4.5 & 20.6 & 746 & 623 & 2000 & 1082 & 1635 & 5000 \\
\hline & all type & 14.4 & 6.2 & 33.2 & 675 & 2004 & 10,299 & 1810 & 3157 & 11,600 \\
\hline
\end{tabular}


Table 4. Comparison of MFLIs with Separation Factors $(\alpha)$, Pervaporation Separation Indexes (PSIs), and Selectivities $(\beta)$ in Ethanol-Water Pervaporation

\begin{tabular}{|c|c|c|c|c|c|c|}
\hline org or hydr & membrane category & $\alpha[-]$ & PSI $\left[\mathrm{kg} / \mathrm{m}^{2} \mathrm{~h}\right]$ & $\beta[-]$ & MFLI $[-]$ & ref. \\
\hline \multirow[t]{3}{*}{ orgPV } & silicalite-1 with PDMS coating - SS s. & 125 & 17 & 41 & 4.5 & Matsuda et al., $2002^{48}$ \\
\hline & silicalite-1 - SS s. & 60 & 45 & 18 & 3.9 & Sano et al., $1994^{49}$ \\
\hline & silicalite-1 - SS s. & 59 & 13 & 18 & 3.8 & Sano et al., $1997^{50}$ \\
\hline \multirow[t]{3}{*}{ hydrPV } & $\mathrm{Alg} / \mathrm{DNA}-\mathrm{Mg}^{2+}$ & 6500 & 65 & 3883 & 33.2 & Uragami et al., $2015^{51}$ \\
\hline & cationic PVA/GA & 709 & 63 & 2680 & 24.6 & Praptowidodo, $2005^{52}$ \\
\hline & anionic PVA/GA & 837 & 72 & 2587 & 24.5 & Praptowidodo, $2005^{52}$ \\
\hline
\end{tabular}

Table 5. Evaluation and Summary of MFLIs, PSIs, and Separation Factors in Isobutanol-Water Separation

\begin{tabular}{|c|c|c|c|c|c|c|c|c|c|}
\hline \multirow[b]{2}{*}{ membrane category } & \multicolumn{3}{|c|}{ MFLI } & \multicolumn{3}{|c|}{ PSI } & \multicolumn{3}{|c|}{ separation factor } \\
\hline & $\mathrm{AVE}^{1}$ & $\mathrm{SDV}^{1}$ & $\operatorname{MAX}^{1}$ & AVE & SDV & MAX & AVE & SDV & MAX \\
\hline organophilic membranes & 7.2 & 2.8 & 9.8 & 150 & 114 & 295 & 33 & 4 & 40 \\
\hline hydrophilic membranes & 8.0 & 7.7 & 21.7 & 2862 & 4056 & 12,533 & 1301 & 1964 & 6010 \\
\hline
\end{tabular}

Table 6. Comparison of MFLIs with Separation Factors $(\alpha)$, Pervaporation Separation Indexes (PSIs), and Selectivities $(\beta)$ in Isobutanol-Water Pervaporation

\begin{tabular}{|c|c|c|c|c|c|c|}
\hline org or hydr & membrane category & $\alpha[-]$ & PSI $\left[\mathrm{kg} / \mathrm{m}^{2} \mathrm{~h}\right]$ & $\beta[-]$ & $\operatorname{MFLI}[-]$ & ref. \\
\hline \multirow[t]{3}{*}{ orgPV } & $(\mathrm{TX}-\mathrm{PDMS})_{n}$ & 38 & 248 & 760 & 9.8 & Schnabel et al., $1998^{53}$ \\
\hline & $(\mathrm{T}-\mathrm{PDMS})_{n}$ & 37 & 295 & 569 & 9.5 & Schnabel et al., $1998^{53}$ \\
\hline & Sulzer PERVAP 4060 & 30 & 29 & 450 & 3.2 & Toth et al., $2015^{23}$ \\
\hline \multirow[t]{3}{*}{ hydrPV } & Sulzer PERVAP 1510 & 6010 & 3005 & 10,000 & 21.7 & Toth et al., $2015^{23}$ \\
\hline & Sulzer PERVAP 1510 & 890 & 3760 & 2200 & 21.2 & Valentinyi et al., $2014^{54}$ \\
\hline & zeolite LTA, porous $\mathrm{Al}_{2} \mathrm{O}_{3}$ & 2811 & 12,533 & 1400 & 5.7 & Huang et al., $2014^{55}$ \\
\hline
\end{tabular}

Table 7. Evaluation and Summary of MFLIs, PSIs, and Separation Factors in Tetrahydrofuran-Water Separation

\begin{tabular}{|c|c|c|c|c|c|c|c|c|c|}
\hline \multirow[b]{2}{*}{ membrane category } & \multicolumn{3}{|c|}{ MFLI } & \multicolumn{3}{|c|}{ PSI } & \multicolumn{3}{|c|}{ separation factor } \\
\hline & AVE & SDV & MAX & AVE & SDV & MAX & AVE & SDV & MAX \\
\hline organophilic membranes & 9.7 & 7.4 & 20.4 & 80 & 119 & 308 & 96 & 36 & 170 \\
\hline \multicolumn{10}{|l|}{ hydrophilic membranes } \\
\hline zeolite & 17.0 & 1.2 & 18.4 & 5634 & 8305 & 21,358 & 6128 & 8056 & 20,000 \\
\hline PVA & 17.3 & 2.8 & 21.3 & 99 & 87 & 217 & 369 & 204 & 591 \\
\hline other & 14.2 & 3.8 & 21.9 & 7882 & 11,953 & 46,986 & 23,854 & 38,186 & 89,900 \\
\hline all type & 15.4 & 3.5 & 21.9 & 6010 & 10,303 & 46,986 & 15,862 & 31,334 & 89,900 \\
\hline
\end{tabular}

Table 8. Evaluation and Summary of MFLIs, PSIs, and Separation Factors in N-Butanol-Water Separation

\begin{tabular}{|c|c|c|c|c|c|c|c|c|c|}
\hline \multirow[b]{2}{*}{ membrane category } & \multicolumn{3}{|c|}{ MFLI } & \multicolumn{3}{|c|}{ PSI } & \multicolumn{3}{|c|}{ separation factor } \\
\hline & AVE & SDV & MAX & AVE & SDV & MAX & AVE & SDV & MAX \\
\hline \multicolumn{10}{|l|}{ organophilic membranes } \\
\hline PDMS & 1.5 & 0.5 & 2.4 & 38 & 38 & 129 & 36 & 14 & 66 \\
\hline other & 1.0 & 0.4 & 1.5 & 136 & 299 & 979 & 31 & 30 & 104 \\
\hline all type & 1.3 & 0.5 & 2.4 & 77 & 192 & 979 & 34 & 21 & 104 \\
\hline hydrophilic membranes & 2.9 & 0.3 & 3.5 & 27,026 & 49,435 & 125,099 & 18,402 & 35,761 & 90,000 \\
\hline
\end{tabular}

Table 9. Evaluation and Summary of MFLIs, PSIs, and Separation Factors in Isopropanol-Water Separation

\begin{tabular}{|c|c|c|c|c|c|c|c|c|c|}
\hline \multirow[b]{2}{*}{ membrane category } & \multicolumn{3}{|c|}{ MFLI } & \multicolumn{3}{|c|}{ PSI } & \multicolumn{3}{|c|}{ separation factor } \\
\hline & AVE & SDV & MAX & AVE & SDV & MAX & AVE & SDV & MAX \\
\hline organophilic membranes & 0.8 & 0.3 & 1.4 & 7 & 8 & 22 & 11 & 8 & 32 \\
\hline \multicolumn{10}{|l|}{ hydrophilic membranes } \\
\hline PVA & 8.7 & 0.7 & 9.1 & 265 & 330 & 1272 & 2865 & 5186 & 17,991 \\
\hline chitosan & 8.8 & 2.4 & 14.9 & 491 & 497 & 1339 & 1493 & 1276 & 4277 \\
\hline other & 9.2 & 1.9 & 15.0 & 6039 & 13,462 & 47,398 & 5178 & 8163 & 30,000 \\
\hline all type & 8.9 & 1.7 & 15.0 & 2260 & 8042 & 47,398 & 3214 & 5746 & 30,000 \\
\hline
\end{tabular}

chemical process design. It is determined that the parameters can be calculated from each other for the different membrane alternatives. It is found that the membrane of the highest MFLI has also the highest selectivity. However, this is not the case 
with the other membrane characterizing parameters. Therefore, an algorithm is presented for the calculation of the different membrane characterizing parameters for the efficient support of chemical process design. First, the calculation of the MFLI is suggested to determine the selection between pervaporation and distillation. If the MFLI suggests one to use pervaporation, the determination of selectivity is recommended for the recognition of optimal operating parameters, pressure, temperature, etc. Lastly, the calculation of PSI can summarize the information of purity with separation factor value, yield, and fluxes.

\section{COMPUTATIONAL METHODS}

Figure 7 introduces the possible operating boundaries of flash distillation.

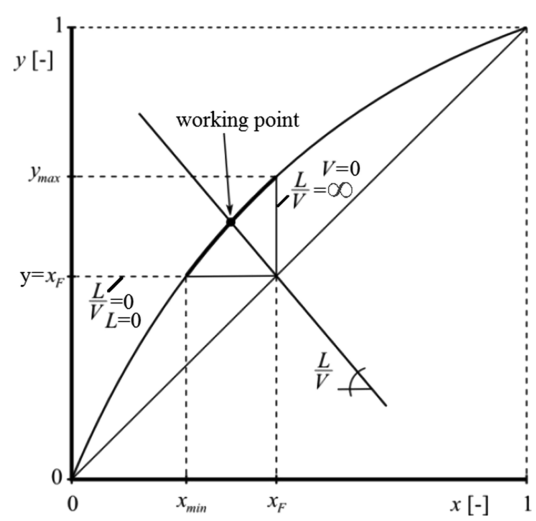

Figure 7. Possible operating boundaries of flash distillation in liquidvapor equilibrium. ${ }^{1}$ Reprinted with permission from ref 1 . Copyright 2018 American Chemical Society.

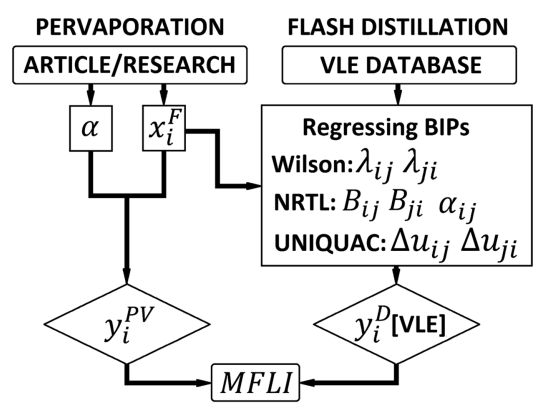

Figure 8. General process of the determination of MFLIs.

The available theoretical maximum vapor data $\left(y_{\max }\right)$ is the equilibrium composition of the feed, and the corresponding $y_{i}^{D}$ data has to be established as a function of $x_{i}^{F}$, as can be seen in Figure 7.

Refereed vapor-liquid equilibrium data has to be applied to find the appropriate $y_{i}^{D}$. Information can be found in the Vapor-Liquid Equilibrium (VLE) Data Collection from DECHEMA $^{56}$ in the database of flowsheet simulators (ChemCAD, Aspen Plus, Aspen Hysys, etc.). In most of the cases, enough exact VLE data is not available. Thus, regression processes of thermodynamic models are offered for the definition of accurate and appropriate $y_{i}^{D}$. Three thermodynamic models are described, which is offered for the calculation of $y_{i}^{D}$ in the case of the determination of MFLIs. The paper extends the calculation of MFLI with this presentation.

The activity coefficient model presented by Wilson ${ }^{57}$ aims to incorporate two adjustable interaction parameters and clean constituent's molar volumes and to specify the excess Gibbs energy of binary solution, therefore modeling equilibrium. The activity coefficients can be calculated by eq $7:^{58}$

$$
\ln \gamma_{k}=1-\ln \left(\sum_{i} x_{i} \Lambda_{k i}\right)-\sum_{j}\left(\frac{x_{j} \Lambda_{j k}}{\sum_{i} x_{i} \Lambda_{j i}}\right)
$$

where the values of $\Lambda_{\mathrm{ij}}$ can be calculated from liquid molar volumes of clean constituents $\left(V_{i}, V_{j}\right)$ and $\lambda_{\mathrm{ij}}$ and $\lambda_{\mathrm{ij}}$ are interaction parameters of the Wilson model given in $\mathrm{cal} / \mathrm{g} \cdot \mathrm{mol}$ :

$$
\Lambda_{i j}=\left(V_{j} / V_{i}\right) \times \exp \left[-\left(\lambda_{i j}-\lambda_{j i}\right) / R T\right]
$$

The main equation of the "non-random two-liquid model" $(\mathrm{NRTL})^{59}$ model is displayed as

$$
\ln \gamma_{i}=\frac{\sum_{j}^{n} x_{j} \tau_{j i} G_{j i}}{\sum_{k}^{n} x_{k} G_{k i}}+\sum_{j}^{n} \frac{x_{j} G_{i j}}{\sum_{k}^{n} x_{k} G_{k j}}\left(\tau_{i j}-\frac{\sum_{m}^{n} x_{m} \tau_{m j} G_{m j}}{\sum_{k}^{n} x_{k} G_{k j}}\right)
$$

where

$$
G_{i j}=\exp \left(-\alpha_{i j} \times \tau_{\mathrm{ij}}\right)
$$

and

$$
\tau_{i j}=A_{i j}+\frac{B_{i j}}{T}+C_{i j} \times \ln (T)+D_{i j} \times T
$$

$B_{i j}, B_{j i}$ and $\alpha_{i j}$ are used by the NRTL equation under the regression of binary interaction parameters (BIPs) in the flowsheet simulator, e.g., ChemCAD. ${ }^{1}$

The "universal quasichemical model" (UNIQUAC) ${ }^{60}$ combines together an enthalpic (residual contribution) term and an entropic (also called combinatorial contribution) term for the determination of activity coefficients. The combinato-

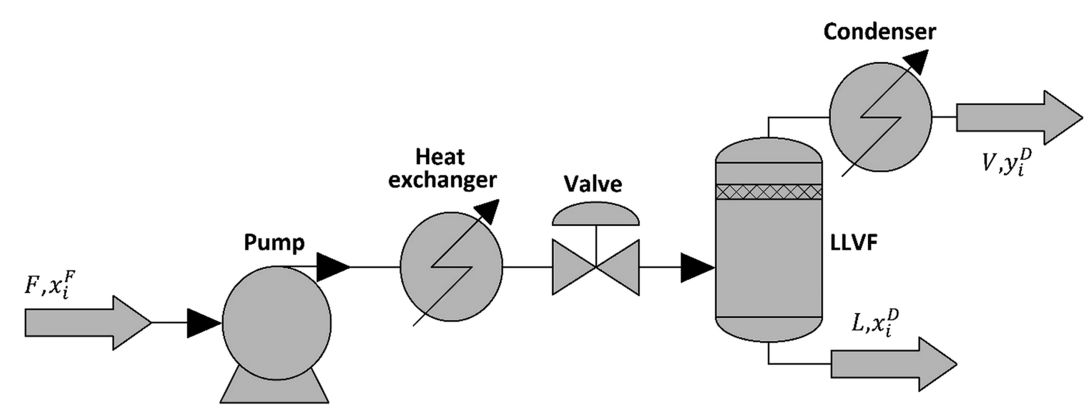

Figure 9. Schematic figure of flash distillation. ${ }^{31}$ Reprinted with permission from ref 31. Copyright 2016 Elsevier. 


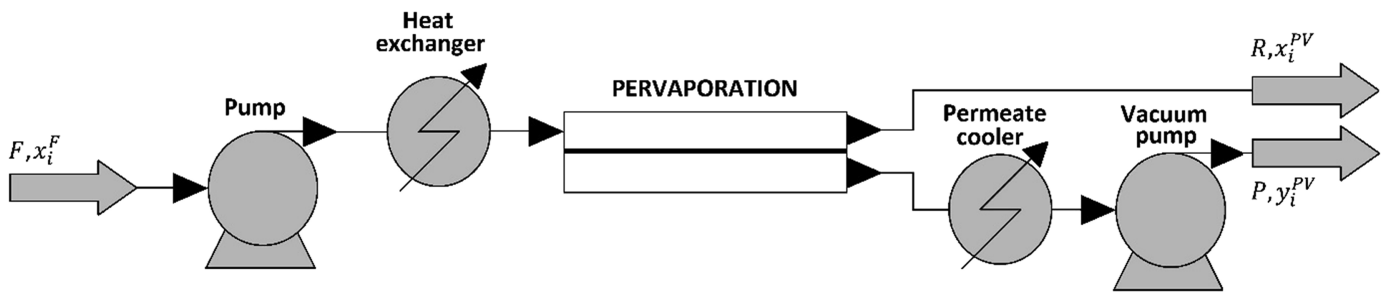

Figure 10. Schematic figure of pervaporation. ${ }^{31}$ Reprinted with permission from ref 31 . Copyright 2016 Elsevier.

Table 10. Examined Mixtures $(100 \mathrm{kPa})^{61}$

\begin{tabular}{|c|c|c|c|c|c|}
\hline \multirow[b]{2}{*}{ mixtures } & \multicolumn{3}{|c|}{ NRTL parameter } & \multicolumn{2}{|c|}{$\begin{array}{l}\text { azeotropic } \\
\text { comp. }\end{array}$} \\
\hline & $B_{i j}[-]$ & $B_{j i}[-]$ & $\alpha_{\mathrm{ij}}[-]$ & [w.f.] & {$\left[{ }^{\circ} \mathrm{C}\right]$} \\
\hline $\begin{array}{l}\text { water-methyl } \\
\text { alcohol }\end{array}$ & 307.166 & -24.4933 & 0.3001 & & \\
\hline water-ethyl alcohol & 670.441 & -55.1681 & 0.3031 & 95.7 & 78.3 \\
\hline $\begin{array}{l}\text { water-isobutyl } \\
\text { alcohol }\end{array}$ & 1068.12 & 95.5182 & 0.3291 & 67.7 & 89.6 \\
\hline $\begin{array}{l}\text { water- } \\
\text { tetrahydrofuran }\end{array}$ & 953.251 & 449.411 & 0.4306 & 93.3 & 63.4 \\
\hline water-N-butanol & 1468.34 & 215.427 & 0.3634 & 57.5 & 92.7 \\
\hline water-isopropanol & 832.981 & 20.0554 & 0.3255 & 88.0 & 80.1 \\
\hline
\end{tabular}

rial term is the effect coming from the molecule shape (that could be calculated from group contributions), the residual term from interactions between molecules: ${ }^{58}$

$$
\begin{aligned}
& \ln \gamma_{i}=\ln \gamma_{i}^{C}+\ln \gamma_{i}^{R} \\
& \ln \gamma_{i}^{C}=\left(1-V_{i}+\ln \left(V_{i}\right)\right)-\frac{z}{2} q_{1}\left(1-\frac{V_{i}}{F_{i}}+\ln \left(\frac{V_{i}}{F_{i}}\right)\right) \\
& \ln \gamma_{i}^{R}=q_{i}\left(1-\ln \frac{\sum_{j} q_{j} x_{j} \tau_{j i}}{\sum_{j} q_{j} x_{j}}-\sum_{j} \frac{q_{j} x_{j} \tau_{i j}}{\sum_{k} q_{k} x_{k} \tau_{k j}}\right)
\end{aligned}
$$

where $\tau_{i j}=\exp \left(-\Delta u_{i j} / R T\right)$, where $\Delta u_{i j}$ is the binary interaction parameter. The values are defined as $\Delta u_{i j}=u_{i j}$ $u_{i i}$ incorporating the interactions between different and similar molecules. ${ }^{58}$ It must be mentioned that the applied thermodynamic model has to be remarked in every cases. The selection of the model should be confirmed in the literature.

Using eq $15, y_{i}^{P V}$ can be calculated easily:

$$
y_{i}^{P V}=\frac{\alpha \times x_{i}^{F}}{(\alpha-1) \times x_{i}^{F}+1}
$$

It has to be also mentioned that the comparison is based on the best available permeate concentration. The main permeable component has to be distributed by each other: organic concentration in the permeate product at organophilic PV with an appropriate equilibrium organic concentration and, in contrast, water concentration in the permeate product at hydrophilic pervaporation with an appropriate equilibrium water concentration. Figure 8 introduces the general determination process of membrane flash index (MFLI). ${ }^{1}$

The Supporting Information contains an example of the determination of MFLIs in Part I. Figures 9 and 10 present the figures of two unit operations, simple flash distillation, and pervaporation. These figures show the parameters to pair each other: liquid equilibrium with vapor equilibrium value $\left(y_{i}^{D}\right)$ in flash distillation and $y_{i}^{P V}$ with the $y_{i}^{D} .^{1}$

Six binary aqueous mixtures are selected for the exemplification of correlation between distillation and pervaporation (see Table 10). In the case of vapor-liquid equilibrium data, the "non-random two-liquid model" (NRTL) thermodynamic model ${ }^{59}$ is applied.

The comparison of PV and flash distillation is studied only for such separation cases, where the target is not azeotrope fractionation. ${ }^{1}$ It can be mentioned that improved separation achievement can be gained by applying rectification, although pervaporation is often the preferred solution in the case of the treatment of the azeotropic mixtures. ${ }^{31,62}$

\section{ASSOCIATED CONTENT}

\section{Supporting Information}

The Supporting Information is available free of charge at https://pubs.acs.org/doi/10.1021/acsomega.0c01063.

Example calculation for membrane flash index (MFLI), separation of methanol and water, separation of ethanol and water, separation of isobutanol and water, separation of tetrahydrofuran and water, separation of $N$-butanol and water, separation of isopropanol and water, nomenclature, and references (PDF)

\section{AUTHOR INFORMATION}

\section{Corresponding Author}

Andras Jozsef Toth - Department of Chemical and

Environmental Process Engineering, Budapest University of Technology and Economics, HU 1111 Budapest, Hungary; Institute of Chemistry, University of Miskolc, HU 3515 Miskolc, Hungary; 이이이.org/0000-0002-5787-8557; Phone: +36 1 463 1494; Email: andrasjozseftoth@edu.bme.hu

\section{Authors}

Botond Szilagyi - Department of Chemical and Environmental Process Engineering, Budapest University of Technology and Economics, HU 1111 Budapest, Hungary

Daniel Fozer - Department of Chemical and Environmental Process Engineering, Budapest University of Technology and Economics, HU 1111 Budapest, Hungary; 이이.org/00000002-1712-8989

Eniko Haaz - Department of Chemical and Environmental Process Engineering, Budapest University of Technology and Economics, HU 1111 Budapest, Hungary

Asmaa Khaled Mohamed Selim - Department of Chemical and Environmental Process Engineering, Budapest University of Technology and Economics, HU 1111 Budapest, Hungary; Chemical Engineering Department, National Research Centre, EG 12622 Cairo, Egypt

Milán Szöri - Institute of Chemistry, University of Miskolc, HU 3515 Miskolc, Hungary; @ orcid.org/0000-0003-4895-0999 
Bela Viskolcz - Institute of Chemistry, University of Miskolc, HU 3515 Miskolc, Hungary

Peter Mizsey - Department of Chemical and Environmental Process Engineering, Budapest University of Technology and Economics, HU 1111 Budapest, Hungary; Institute of Chemistry, University of Miskolc, HU 3515 Miskolc, Hungary; (1) orcid.org/0000-0002-6976-6210

Complete contact information is available at:

https://pubs.acs.org/10.1021/acsomega.0c01063

\section{Notes}

The authors declare no competing financial interest.

\section{ACKNOWLEDGMENTS}

This publication was supported by the János Bolyai Research Scholarship of the Hungarian Academy of Sciences, ÚNKP-194-BME-416 New National Excellence Program of the Ministry for Innovation and Technology, OTKA 131586, 112699, and 128543. This research was supported by the European Union and the Hungarian State, co-financed by the European Regional Development Fund in the framework of the GINOP-2.3.4-15-2016-00004 project, aimed to promote the cooperation between the higher education and the industry. The research reported in this paper has been supported by the National Research, Development and Innovation Fund (TUDFO/51757/2019-ITM), Thematic Excellence Program.

\section{NOMENCLATURE}

A membrane transfer area $\left[\mathrm{m}^{2}\right]$

$B_{i j} \quad$ NRTL interaction parameter

$B_{j i} \quad$ NRTL interaction parameter

F feed

i component number

j component number

$J_{i} \quad$ flux of component $i\left[\mathrm{~kg} /\left(\mathrm{m}^{2} \mathrm{~h}\right)\right]$

$L \quad$ liquid equilibrium

$P$ permeate

$p_{i 0} \quad$ pure $i$ component vapor pressure [bar]

$p_{3}$ pressure on the permeate side [bar]

$P_{i} / \delta$ permeance of component $i\left[\mathrm{~kg} /\left(\mathrm{m}^{2} \mathrm{hbar}\right)\right]$

$R$ retentate

s. support

$t$ time $[\mathrm{h}]$

$T$ temperature $\left[{ }^{\circ} \mathrm{C}\right]$

$V$ vapor equilibrium

$x_{i}^{F} \quad$ feed alcohol or water weight fraction $[-]$

$x_{i 1}$ concentration of component $i$ in the feed $[\mathrm{m} / \mathrm{m} \%]$

$x_{i}^{D} \quad$ equilibrium liquid alcohol or water weight fraction [ - ]

$y_{i}^{D}$ equilibrium vapor alcohol or water weight fraction $[-]$

$x_{i}^{P V}$ retentate alcohol or water weight fraction $[-]$

$y_{i}^{P V}$ permeate alcohol or water weight fraction $[-]$

\section{Abbreviations}

AVE average

BIPs binary interaction parameter

EtOH ethanol, ethyl alcohol

HPV hydrophilic pervaporation

hydr hydrophilic

IBU isobutanol, isobutyl alcohol

IPA isopropanol

MAX maximum

$\mathrm{MeOH}$ methanol, methyl alcohol

MFLI membrane flash index
NBU $n$-butanol, $n$-butyl alcohol

NRTL non-random two-liquid model

OPV organophilic pervaporation

org organophilic

PDMS polydimethylsiloxane

PSI pervaporation separation index $\left[\mathrm{kg} /\left(\mathrm{m}^{2} \mathrm{~h}\right)\right]$

PVA polyvinyl alcohol

PV pervaporation

SDV standard deviation

THF tetrahydrofuran

$\Delta u_{i j} \quad$ UNIQUAC interaction parameter

$\Delta u_{j i} \quad$ UNIQUAC interaction parameter

VLE vapor-liquid equilibrium

w.f. weight fraction

\section{Greek Letters}

$\alpha$ separation factor

$\alpha_{i j}$ NRTL interaction parameter

$\alpha_{j i}$ NRTL interaction parameter

$\beta$ selectivity

$\gamma_{i 1}$ activity coefficient of component $i$ in the feed

$\delta$ membrane thickness $[\mu \mathrm{m}]$

$\lambda_{i j}$ Wilson interaction parameter

$\lambda_{j i}$ Wilson interaction parameter

\section{REFERENCES}

(1) Toth, A. J.; Haaz, E.; Valentinyi, N.; Nagy, T.; Tarjani, A. J.; Fozer, D.; Andre, A.; Khaled Mohamed, S. A.; Solti, S.; Mizsey, P. Selection between Separation Alternatives: Membrane Flash Index (MFLI). Ind. Eng. Chem. Res. 2018, 57, 11366-11373.

(2) Manczinger, J. Flash Distillation. In Chemical Unit Operations Laboratory; Budapest University of Technology and Economics: Budapest, 2014; pp 66-74.

(3) Hsueh, C. L.; Kuo, J. F.; Huang, Y. H.; Wang, C. C.; Chen, C. Y. Separation of ethanol-water solution by poly(acrylonitrile-co-acrylic acid) membranes. Sep. Purif. Technol. 2005, 41, 39-47.

(4) Koczka, K.; Manczinger, J.; Mizsey, P.; Fonyo, Z. Novel hybrid separation processes based on pervaporation for THF recovery. Chem. Eng. Process. 2007, 46, 239-246.

(5) Lipnizki, F.; Field, R. W.; Ten, P.-K. Pervaporation-based hybrid process: a review of process design, applications and economics. J. Membr. Sci. 1999, 153, 183-210.

(6) Van Baelen, D.; Van der Bruggen, B.; Van den Dungen, K.; Degreve, J.; Vandecasteele, C. Pervaporation of water-alcohol mixtures and acetic acid-water mixtures. Chem. Eng. Sci. 2005, 60, $1583-1590$.

(7) Van Hoof, V.; Van den Abeele, L.; Buekenhoudt, A.; Dotremont, C.; Leysen, R. Economic comparison between azeotropic distillation and different hybrid systems combining distillation with pervaporation for the dehydration of isopropanol. Sep. Purif. Technol. 2004, 37, $33-49$.

(8) Nik, O. G.; Moheb, A.; Mohammadi, T. Separation of ethylene glycol/water mixtures using $\mathrm{NaA}$ zeolite membranes. Chem. Eng. Technol. 2006, 29, 1340-1346.

(9) Rhim, J.-W.; Park, H. B.; Lee, C.-S.; Jun, J.-H.; Kim, D. S.; Lee, Y. M. Crosslinked poly(vinyl alcohol) membranes containing sulfonic acid group: Proton and methanol transport through membranes. J. Membr. Sci. 2004, 238, 143-151.

(10) Cunha, V. S.; Paredes, M. L. L.; Borges, C. P.; Habert, A. C.; Nobrega, R. Removal of aromatics from multicomponent organic mixtures by pervaporation using polyurethane membranes: experimental and modeling. J. Membr. Sci. 2002, 206, 277-290.

(11) Ray, S.; Ray, S. K. Separation of organic mixtures by pervaporation using crosslinked and filled rubber membranes. J. Membr. Sci. 2006, 285, 108-119. 
(12) Smitha, B.; Suhanya, D.; Sridhar, S.; Ramakrishna, M. Separation of organic-organic mixtures by pervaporation-a review. J. Membr. Sci. 2004, 241, 1-21.

(13) Mandal, S.; Pangarkar, V. G. Separation of methanol-benzene and methanol-toluene mixtures by pervaporation: effects of thermodynamics and structural phenomenon. J. Membr. Sci. 2002, 201, 175-190.

(14) Konieczny, K.; Bodzek, M.; Panek, D. Removal of volatile compounds from the wastewaters by use of pervaporation. Desalination 2008, 223, 344-348.

(15) Lipnizki, F.; Hausmanns, S.; Ten, P.-K.; Field, R. W.; Laufenberg, G. Organophilic pervaporation: prospects and performance. Chem. Eng. J. 1999, 73, 113-129.

(16) Aroujalian, A.; Belkacemi, K.; Davids, S. J.; Turcotte, G.; Pouliot, Y. Effect of Protein on Flux and Selectivity in Pervaporation of Ethanol from a Dilute Solution. Sep. Sci. Technol. 2003, 38, 32393247.

(17) Ki Hong, Y.; Hi Hong, W. Influence of ceramic support on pervaporation characteristics of IPA/water mixtures using PDMS/ ceramic composite membrane. J. Membr. Sci. 1999, 159, 29-39.

(18) Liang, L.; Dickson, J. M.; Jiang, J.; Brook, M. A. Effect of low flow rate on pervaporation of 1,2-dichloroethane with novel polydimethylsiloxane composite membranes. J. Membr. Sci. 2004, 231, 71-79.

(19) González-Velasco, J. R.; González-Marcos, J. A.; López-Dehesa, C. Pervaporation of ethanol-water mixtures through poly(1trimethylsilyl-1-propyne) (PTMSP) membranes. Desalination 2002, $149,61-65$.

(20) Oh, H. K.; Song, K. H.; Lee, K. R.; Rim, J. M. Prediction of sorption and flux of solvents through PDMS membrane. Polymer 2001, 42, 6305-6312.

(21) Favre, E. Temperature polarization in pervaporation. Desalination 2003, 154, 129-138.

(22) Hasanoğlu, A.; Salt, Y.; Keleşer, S.; Özkan, S.; Dinçer, S. Pervaporation separation of ethyl acetate-ethanol binary mixtures using polydimethylsiloxane membranes. Chem. Eng. Process. 2005, 44, $375-381$.

(23) Toth, A. J.; Andre, A.; Haaz, E.; Mizsey, P. New horizon for the membrane separation: Combination of organophilic and hydrophilic pervaporations. Sep. Purif. Technol. 2015, 156, 432-443.

(24) Nguyen, T. Q.; Nobe, K. Extraction of organic contaminants in aqueous solutions by pervaporation. J. Membr. Sci. 1987, 30, 11-22.

(25) Devaine, K. M.; Meier, A. J.; Slater, C. S. In Pervaporation for the recovery of MEK and other solvents using organophilic membranes In. 7th International Conference on Pervaporation Process in the Chemical Industry, Reno, Nevada, 1995; Bakish, R., Ed. Bakish Materials Corp.: Reno, Nevada, 1995; p 218.

(26) Zhang, S. Q.; Fouda, A. E.; Matsuura, T. A study of pervaporation of aqueous benzyl alcohol solution by polydimethylsiloxane membrane. J. Membr. Sci. 1992, 70, 249-255.

(27) Toth, A. J. Liquid Waste Treatment with Physicochemical Tools for Environmental Protection. $\mathrm{PhD}$ Thesis, Budapest University of Technology and Economics: Budapest, Hungary, 2015.

(28) Feng, X.; Huang, R. Y. M. Liquid Separation by Membrane Pervaporation: A Review. Ind. Eng. Chem. Res. 1997, 36, 1048-1066.

(29) Baker, R. W. Membrane Technology and Applications, 3rd edition ed.; Wiley: 2012.

(30) Neel, J. Introduction to pervaporation. In Pervaporation Membrane Separation Processes; Huang, R. Y. M., Ed. Elsevier: Amsterdam, 1991; pp 1-109.

(31) Toth, A. J.; Andre, A.; Haaz, E.; Mizsey, P. Modelling of organophilic pervaporation to compete with distillation. In 26th European Symposium on Computer Aided Process Engineering ESCAPE 26; Elsevier: Portoroz, Slovenia, 12-15 June 2016., Portoroz, 2016; pp 343-348.

(32) Svang-Ariyaskul, A.; Huang, R. Y. M.; Douglas, P. L.; Pal, R.; Feng, X.; Chen, P.; Liu, L. Blended chitosan and polyvinyl alcohol membranes for the pervaporation dehydration of isopropanol. $J$. Membr. Sci. 2006, 280, 815-823.
(33) Huang, B.; Liu, Q.; Caro, J.; Huang, A. Iso-butanol dehydration by pervaporation using zeolite LTA membranes prepared on 3aminopropyltriethoxysilane-modified alumina tubes. J. Membr. Sci. 2014, 455, 200-206.

(34) Samanta, H. S.; Ray, S. K. Separation of ethanol from water by pervaporation using mixed matrix copolymer membranes. Sep. Purif. Technol. 2015, 146, 176-186.

(35) Crespo, J. G.; Brazinha, C. Fundamentals of pervaporation. In Pervaporation, Vapour Permeation and Membrane Distillation, Woodhead Publishing: Oxford, 2015; pp 3-17.

(36) Baker, R. W.; Wijmans, J. G.; Huang, Y. Permeability, permeance and selectivity: A preferred way of reporting pervaporation performance data. J. Membr. Sci. 2010, 348, 346-352.

(37) Hinchliffe, A. B.; Porter, K. E. A Comparison of Membrane Separation and Distillation. Chem. Eng. Res. Des. 2000, 78, 255-268.

(38) Hinchliffe, A. B.; Porter, K. E. Gas Separation Using Membranes. 1. Optimization of the Separation Process Using New Cost Parameters. Ind. Eng. Chem. Res. 1997, 36, 821-829.

(39) Porter, K. E.; Hinchliffe, A. B.; Tighe, B. J. Gas Separation Using Membranes. 2. Developing a New Membrane for the Separation of Hydrogen and Carbon Monoxide Using the Targeting Approach. Ind. Eng. Chem. Res. 1997, 36, 830-837.

(40) Van Der Bruggen, B.; Luis, P. Pervaporation as a tool in chemical engineering: A new era? Curr. Opin. Chem. Eng. 2014, 4, $47-53$.

(41) Luis, P.; Degrève, J.; der Bruggen, B. V. Separation of methanol-n-butyl acetate mixtures by pervaporation: Potential of 10 commercial membranes. J. Membr. Sci. 2013, 429, 1-12.

(42) Shirazi, Y.; Ghadimi, A.; Mohammadi, T. Recovery of alcohols from water using polydimethylsiloxane-silica nanocomposite membranes: Characterization and pervaporation performance. J. Appl. Polym. Sci. 2012, 124, 2871-2882.

(43) Liu, Q.; Noble, R. D.; Falconer, J. L.; Funke, H. H. Organics/ water separation by pervaporation with a zeolite membrane. J. Membr. Sci. 1996, 117, 163-174.

(44) Bowen, T. C.; Kalipcilar, H.; Falconer, J. L.; Noble, R. D. Pervaporation of organic/water mixtures through B-ZSM-5 zeolite membranes on monolith supports. J. Membr. Sci. 2003, 215, 235-247.

(45) El-Gendi, A.; Abdallah, H. Selectivity performance for polyamide- 6 membranes using pervaporation of water/methanol mixtures. Desalin. Water Treat. 2013, 51, 3263-3272.

(46) Peng, F.; Jiang, Z.; Hu, C.; Wang, Y.; Lu, L.; Wu, H. Pervaporation of benzene/cyclohexane mixtures through poly(vinyl alcohol) membranes with and without $\beta$-cyclodextrin. Desalination 2006, 193, 182-192.

(47) Won, W.; Feng, X.; Lawless, D. Separation of dimethyl carbonate/methanol/water mixtures by pervaporation using crosslinked chitosan membranes. Sep. Purif. Technol. 2003, 31, 129-140.

(48) Matsuda, H.; Yanagishita, H.; Negishi, H.; Kitamoto, D.; Ikegami, T.; Haraya, K.; Nakane, T.; Idemoto, Y.; Koura, N.; Sano, T. Improvement of ethanol selectivity of silicalite membrane in pervaporation by silicone rubber coating. J. Membr. Sci. 2002, 210, 433-437.

(49) Sano, T.; Yanagishita, H.; Kiyozumi, Y.; Mizukami, F.; Haraya, K. Separation of ethanol/water mixture by silicalite membrane on pervaporation. J. Membr. Sci. 1994, 95, 221-228.

(50) Sano, T.; Ejiri, S.; Yamada, K.; Kawakami, Y.; Yanagishita, H. Separation of acetic acid-water mixtures by pervaporation through silicalite membrane. J. Membr. Sci. 1997, 123, 225-233.

(51) Uragami, T.; Banno, M.; Miyata, T. Dehydration of an ethanol/ water azeotrope through alginate-DNA membranes cross-linked with metal ions by pervaporation. Carbohydr. Polym. 2015, 134, 38-45.

(52) Praptowidodo, V. S. Influence of swelling on water transport through PVA-based membrane. J. Mol. Struct. 2005, 739, 207-212.

(53) Schnabel, S.; Roizard, D.; Nguyen, T.; Lochon, P.; Aptel, P. Synthesis of novel block siloxane polymers for the removal of butanols from aqueous feed solutions. Colloids Surf. A 1998, 138, 335-343. 
(54) Valentínyi, N.; Mizsey, P. Comparison of pervaporation models with simulation of hybrid separation processes. Period. Polytech. Chem. Eng. 2014, 58, 7-14.

(55) Huang, S.-H.; Liu, Y.-Y.; Huang, Y.-H.; Liao, K.-S.; Hu, C.-C.; Lee, K.-R.; Lai, J.-Y. Study on characterization and pervaporation performance of interfacially polymerized polyamide thin-film composite membranes for dehydrating tetrahydrofuran. J. Membr. Sci. 2014, 470, 411-420.

(56) Gmehling, J.; Onken, U. Vapor-Liquid Equilibrium Data Collection: Aqueous-Organic Systems; DECHEMA: Frankfurt/Main, Germany, 1977.

(57) Wilson, G. M. Vapor-Liquid Equilibrium. XI. A New Expression for the Excess Free Energy of Mixing. J. Am. Chem. Soc. 1964, 86, 127-130.

(58) Havasi, D. Separation studies on mixtures generated in biomass conversion. $\mathrm{PhD}$ Thesis, Budapest University of Technology and Economics, Budapest, Hungary, 2018.

(59) Renon, H.; Prausnitz, J. M. Local compositions in thermodynamic excess functions for liquid mixtures. AIChE J. 1968, $14,135-144$.

(60) Abrams, D. S.; Prausnitz, J. M. Statistical Thermodynamics of Liquid Mixtures: A New Expression for the Excess Gibbs Energy of Partly or Completely Miscible Systems. AIChE J. 1975, 21, 116-128.

(61) Marsden, C. Solvents And Allied Substances Manual With Solubility Chart; Cleaver-Hume and Elsevier: London, 1954.

(62) Fontalvo, J.; Cuellar, P.; Timmer, J. M. K.; Vorstman, M. A. G.; Wijers, J. G.; Keurentjes, J. T. F. Comparing Pervaporation and Vapor Permeation Hybrid Distillation Processes. Ind. Eng. Chem. Res. 2005, 44, 5259-5266. 